\title{
Casa modernista de Campinas
}

Silvia Amaral Palazzi Zakia*

\section{Resumo}

O artigo disserta especificamente sobre a primeira obra realizada pelo arquiteto campineiro Mário Penteado, formado na Escola Nacional de Belas Artes, em 1931. Trata-se da casa concebida para seu pai, em 1934.

Analisa a edificação modernista construída no exato momento de implantação do plano de modernização do espaço urbano de Campinas, elaborado por Prestes Maia, e intitulado Plano de Melhoramentos Urbanos.

Palavras-chave: Arquitetura modernista. Neocolonial. Art déco.

\section{Campinas' modernist house}

\begin{abstract}
The article discuss specifically about the first work realized by Mário Penteado, the architect from Campinas, graduated by Escola Nacional de Belas Artes, in 1931. It is about a house designed for his father, in 1934.

It analyses the modernist building constructed in the exact moment of implanting of modernizing urbain space plan for Campinas elaborated by Prestes Maia, intitled Plano de Melhoramentos Urbanos.
\end{abstract}

Keywords: Modernist architecture. Neocolonial. Art deco. 
Esse artigo traz uma abordagem da primeira manifestação da arquitetura modernista de Campinas. Trata-se da casa concebida e construída pelo arquiteto Mário Penteado, em 1934.

A casa, que representa um momento histórico significativo da paisagem urbana de Campinas, foi construída em sintonia com os princípios modernizantes que nortearam as alterações urbanas pelas quais a cidade passou durante as décadas de 1930, 1940 e 1950.

Em 1934, a Prefeitura Municipal contratou Prestes Maia para desenvolver um plano de urbanismo, intitulado Plano de Melhoramentos Urbanos, que em linhas gerais objetivava ordenar o crescimento da cidade e devolver ao poder público o controle do espaço urbano.

Nesse ambiente progressista, o recém-formado arquiteto Mário Penteado constrói a pioneira casa modernista de Campinas.

Mário de Camargo Penteado, natural de Campinas, descendente da aristocracia rural cafeeira local, graduou-se engenheiro-arquiteto pela Escola Nacional de Belas Artes (ENBA) na capital cultural do Rio de Janeiro, em 1931. Assistiu, de 1926 a 1931, enquanto estudava, às grandes modificações no contexto político e cultural pelas quais o país passava. Foi um momento de efervescência cultural, sobretudo no campo da disciplina Arquitetura. As questões da modernidade levantadas em oposição ao academicismo reinante na ENBA geraram grandes conflitos. Em 12 de dezembro de 1930, o jovem arquiteto Lúcio Costa foi nomeado diretor da ENBA. Sob sua direção, a escola sofreria uma modificação que alteraria os rumos da arquitetura brasileira. Costa, imbuído pelos ideais apregoados por Le Corbusier, que em 1929 proferiu palestra no salão da escola lotado pelos jovens estudantes e arquitetos, propôs a reformulação do ensino, contratando novos professores alinhados ao novo pensamento. Entre eles estavam o arquiteto Gregori Warchavchik, o pintor Leo Putz e o escultor Celso Antonio. 
Embora houvesse uma insatisfação generalizada dos estudantes em relação ao método do ensino acadêmico, considerado obsoleto e falho, a reforma proposta por Lúcio Costa não continha a formulação de um novo método de ensino. Consistia mais em uma negação aos padrões do ensino vigente do que uma proposição de um novo modelo educacional. Mesmo não tendo sido proposto um modelo de ensino estruturado e consistente, com essa reforma as sementes da arquitetura moderna semeadas por Le Corbusier, em 1929, começaram a germinar na escola. Lúcio Costa enfrentou a oposição ferrenha dos professores conservadores da instituição, fato que culminou com a greve dos alunos e a sua posterior demissão. A herança desse período fértil de discussões ideológicas durante a formação acadêmica de Mário Penteado se faz presente em sua obra. Sua primeira obra na cidade é uma síntese desse momento, que oscilou entre concepções estabelecidas por princípios acadêmicos, e pelo ideário moderno de viés corbusiano.

O curto período de convívio com as discussões sobre a nova arquitetura, na ENBA, não foi suficiente para criar raízes profundas na concepção arquitetônica desenvolvida por Mário Penteado em sua carreira profissional. Era, sobretudo, um arquiteto acadêmico que apreciava a arquitetura moderna realizada por seus colegas de ENBA.

Adquiriu na academia um apuro gráfico em diversas técnicas. Com maestria utilizou o grafite, o nanquim, o pastel e a aquarela. Era de tal ordem a importância dada aos desenhos de apresentação na ENBA que o arquiteto coetâneo Abelardo de Souza relatou que um professor do quarto ano chegou a dizer: "Uma boa aquarela e uma boa árvore podem salvar um mau projeto". (SOUZA, 1978, p.24)

No entanto, desse ensino considerado obsoleto pelos alunos, Penteado herdou, além do já mencionado domínio das representações gráficas de desenho, o controle compositivo do projeto juntamente com um saber técnico-construtivo ampliado pelos estágios em escritórios de arquitetura ou engenharia. 
A experiência adquirida nos estágios em escritórios da capital era uma prática comum entre os estudantes e propiciava um saber técnico indispensável para o exercício da profissão.

Nos escritórios de arquitetura onde, nós alunos íamos trabalhar para adquirir alguma experiência profissional e aprender um pouco de arquitetura, o regime de trabalho era: desenhar para a prefeitura todo o projeto em papel tela [...]. Era fogo! [...] Nosso aprendizado não se limitava ao exercício de um projeto bem estudado e detalhado no desenvolvimento de um serviço. O contato com a obra, ter de resolver no local qualquer dúvida que aparecesse, nos dava muita segurança e maior facilidade para a execução de melhores soluções e novos detalhes. (SOUZA, 1978, p.30-31)

De volta a Campinas, fora do eixo cultural Rio-São Paulo, Mário Penteado iniciou sua carreira profissional trabalhando quase que exclusivamente para o setor privado, tendo como clientela a elite local. Além de atuar como profissional de "prancheta", Penteado exerceu intensa atividade política, divulgando sua profissão junto à sociedade e atuando em entidades de classe. Tendo sido eleito vereador, em 1936, teve oportunidade de participar como membro da Comissão de Melhoramentos Urbanos, instituída em 1936, e que tinha como objetivo discutir as diretrizes a serem adotadas pelo plano de Prestes Maia. Era uma comissão de caráter cívico formada por políticos, técnicos da prefeitura e cidadãos considerados notáveis em suas atividades profissionais, e tinha como atribuição levar as aspirações e anseios da comunidade e das entidades interessadas no desenvolvimento do plano ao urbanista Prestes Maia. Penteado, um dos onze membros da comissão nomeados pelo prefeito, representava como vereador o poder legislativo. Os trabalhos da comissão duraram até 1937 quando foi dissolvida concomitantemente ao poder legislativo municipal, em novembro do referido ano, pelo Estado Novo.

Penteado participou intensamente do processo de modernização urbanística pelo qual a cidade passava, como político e como engenheiro-arquiteto, contribuindo com a construção de inúmeras obras. Foi responsável pela construção de muitas residências situadas principalmente no Cambuí, bairro escolhido pela elite local, e de outros tantos edifícios comerciais localizados na região central da cidade. Pode-se afirmar que 
Penteado participou efetivamente da conformação da paisagem urbana da Campinas das décadas de 1930 e 1940.

Projetou e construiu alguns cinemas, importante programa funcional de época, a primeira rádio de Campinas, PRC-9 Rádio Educadora, clínicas, instituições financeiras como a Caixa Econômica Estadual de São João da Boa Vista, o Banco Nacional da Cidade de São Paulo, a Caixa de Pensões da Zona Mogiana, a Loja Maçônica, hotéis e inclusive a Igreja Matriz de Limeira, cidade próxima a Campinas.

Suas obras firmaram na cidade um padrão de qualidade resultante de projetos detalhados e de construções bem acabadas.

Importante ressaltar que durante os primórdios da década de 1930 poucos eram os profissionais diplomados que atuavam na construção civil. A maioria das obras construídas na cidade ficava a cargo dos profissionais licenciados, mestres de obra que detinham licença para exercer a profissão sem, no entanto, possuírem diploma. Somente a partir de 1934, por conta dos efeitos do Decreto-lei № 23.569 de 11 de dezembro de 1933, que adotava uma proteção intransigente ao título acadêmico e restringia o exercício da profissão aos portadores de diploma, a situação tende a se inverter e gradativamente os licenciados perdem espaço para os diplomados. Entre os anos de 1935 e 1942, somente $25 \%$ dos profissionais atuantes na construção civil eram diplomados.

Entre 1936 e 1942, 80\% das 2012 novas obras construídas na cidade eram atribuídas aos arquitetos e construtores licenciados, como eram designados os profissionais que não possuíam titulação acadêmica, o restante aos diplomados.

Para as obras mais importantes da cidade, isto é, edifícios públicos, edificações de mais de quatro pavimentos, residências de luxo, eram contratados os serviços dos profissionais com diploma. 
Como era pouco conhecida a disciplina arquitetura, Penteado desempenhou também o papel de divulgador da arquitetura na cidade. Como membro do Rotary Club proferiu nessa associação algumas palestras com o intuito de tornar mais conhecida a profissão de arquiteto, entre elas: "O arquiteto e sua missão na coletividade", de 1943 e "Arquitetura Moderna Brasileira", de 1944. Dessa maneira promovia a profissão na cidade.

No período compreendido entre as décadas de 1930 e 1950, Penteado participou ativamente da vida política da cidade; foi vereador, associado, presidente e governador do Rotary Club de Campinas, sócio do Centro de Ciências, Letras e Artes - outra importante instituição cultural campineira -, sócio titular do IAB-RJ, sócio e presidente da Associação de Engenheiros de Campinas. Como arquiteto de prancheta, realizou grande número de obras, participou do V Congresso Panamericano de Arquitetura em Montevidéu - 1940, no qual recebeu Menção Honorífica na categoria "edifícios privados" juntamente com os seguintes arquitetos: Flávio de Carvalho, Severo \& Villares, Jaime Fonseca Rodrigues e Álvaro Botelho. Foi enviado como delegado oficial do Brasil no Congresso Internacional de Arquitetura de Washington (1) - 1939, nomeado pelo Presidente da República por indicação do IAB.

Paralelamente à sua intensa atividade política, sua carreira profissional se desenvolvia com sucesso no escritório situado à Rua Campos Sales, 888. Como integrante de um pequeno grupo de profissionais com nível superior, já no início de sua carreira, Penteado desenvolveu significativos projetos em Campinas e região, tendo várias de suas obras publicadas (2) na revista Arquitetura e Urbanismo (3) (órgão oficial do Instituto de Arquitetos do Brasil, sediado no Rio de Janeiro - publicação bimestral que teve seu primeiro número veiculado em 1936), ao lado de já e futuros expressivos nomes da arquitetura brasileira, como: irmãos Marcelo e Milton Roberto, Ângelo Bruhns, Correa Lima, Lucio Costa, Oscar Niemeyer, Affonso Eduardo Reidy, Jorge Machado Moreira, Carlos Leão, Ernani Mendes de Vasconcellos, Archimedes Memória, Roberto Magno de Carvalho, Augusto Vasconcellos Jr, Paulo de Camargo Almeida, 
Firmino Fernandes Saldanha (4) e de artigos de Luiz Saia e Carmem Portinho, entre outros.

Mário Penteado trabalhou inicialmente em associação com o engenheiro José Gerin Neto, diplomado na Escola Politécnica do Rio de Janeiro em 1930, formando a firma Gerin \& Penteado. Segundo dados retirados do Livro 19 - Registro de Construtores de Campinas, eles teriam trabalhado juntos até 1932 (fls 74). A partir de 1934 começou a trabalhar individualmente (registro individual fls 78). Seu escritório possuía uma estrutura pequena; ele próprio desenvolvia toda parte gráfica dos projetos e era responsável pela sua execução, escolhendo criteriosamente os empreiteiros.

\section{Casa modernista José Ferreira Penteado}

Em 1934, projetou e construiu duas casas concomitantemente, a de Zelina Pontes Ferreira, e a de seu pai, sendo essa última a primeira casa modernista de Campinas, construída seis anos após a casa de Warchavchik (Rua Santa Cruz, na Vila Mariana, em São Paulo).

Penteado colocou sua casa em exposição utilizando a mesma estratégia que Warchavchik utilizara quatro anos antes, quando da exposição da casa modernista da Companhia City na Rua Itápolis, no Pacaembu, em 1930. Penteado inclusive encomendara a Warchavchik, que conhecia como professor na ENBA, as luminárias para sua obra.

A exposição da casa modernista de Penteado obteve grande repercussão na mídia local. Um livro de presença atesta que aproximadamente 400 pessoas visitaram a edificação, membros da comunidade local, familiares, amigos, colegas de profissão, profissionais liberais (médicos, professores, advogados, engenheiros, construtores), muitas mulheres e a significativa presença do representante da igreja - Arcebispo de Goiás, o primeiro a assinar o livro com a seguinte frase. "Se procurar um monumento novíssimo (da arte moderna) olha em redor". Alguns termos reprisados nesse livro repleto de citações que não ultrapassam os lugares-comuns amenos permitem, no 
entanto, a contextualização da época. Entre eles: "originalidade de concepção", "síntese da arte moderna", "lúcida construção", "audaciosa concepção", "[...] arte moderna nascida da inteligência promissora", e muitos comentários sobre o "estilo" moderno da residência.

O artigo publicado no jornal Correio Popular relatou que à inauguração compareceram membros do Sindicato Médico, da Associação de Engenheiros, da Sociedade de Medicina e da imprensa. O objetivo da exposição era divulgar seu trabalho para atrair clientes, pois como enfatiza Lemos:

A prática da arquitetura não depende só do arquiteto e nem de equipes de calculistas, construtores, pedreiros e técnicos os mais variados - ela depende, antes de tudo, do cliente que encomenda e executa o projeto arquitetônico. [...] Um arquiteto de vanguarda [...] não poderia agir e estar construindo por conta própria e depois sair oferecendo a esmo sua obra. (LEMOS, 1983, p.826)

Essa casa era a síntese da experiência vivida quando estudante na ENBA no Rio de Janeiro. Os ares da modernidade ali estavam presentes, sobretudo pela existência da laje-terraço que substituía a cobertura convencional de telhas cerâmicas, do mobiliário com cadeiras de desenho da Bauhaus e de uma estética despojada de ornamentos, que em certa medida pode ser confundida com os estilemas do art déco.

A casa, localizada na confluência da Rua Silva Telles com Rua Santa Cruz, apresenta um jogo volumétrico assimétrico interessante que tirou partido da situação de esquina, criando um terraço semicircular sobre a sala com vista privilegiada. O terreno na confluência das duas ruas possibilitou uma boa visibilidade da edificação no seu todo. A linguagem plástica asséptica anunciava o vanguardismo. Elementos de construção como guarda-corpos tubulares, janelas em forma de escotilhas numa clara alusão náutica, e o próprio revestimento externo em mica, tornavam a edificação um ponto marcante na paisagem urbana ainda pouco ocupada do bairro. Curiosamente, até o nome da rua (Santa Cruz) traz à memória a construção da primeira casa modernista de São Paulo de Warchavchik (1927-1928). 
A casa está implantada obedecendo aos recuos prescritos no novo Código de Construções de 1934 que estava em sintonia com as proposições do Plano de Melhoramentos Urbanos.

Todos os detalhes da obra foram estudados, desde a paginação abstrata no calçamento da rua em mosaico português, o jardim com plantas tropicais, as luminárias desenvolvidas por Warchavchik, o piso de granilite da escada, o revestimento interno das paredes formando na argamassa desenhos geométricos, o mobiliário moderno de cadeiras da Bauhaus (vide fotos no terraço onde estão expostas várias cadeiras modernas, inclusive o modelo de Mart Stam de 1926 - Bauhaus), até a presença do automóvel que foi incorporada, tanto nas fotos como nas plantas, para completar o quadro do "todo moderno e cosmopolita".

A linguagem estética de linhas geométricas desprovidas de ornamentos representava a vanguarda moderna, mas o mesmo não se pode dizer dos aspectos técnicos e da divisão espacial do programa. A planta da casa obedece ao tradicional esquema funcional de divisão entre setores: social, de serviços e íntimo. Uma planta compartimentada vinculada ao sistema construtivo de alvenaria estrutural. Ainda que a cobertura fosse uma laje-terraço, os espaços internos foram divididos segundo as possibilidades que a alvenaria estrutural oferecia. A divisão compartimentada do programa refletia o mesmo modo de viver burguês vigente à época, só que dentro de uma roupagem modernizada, próxima aos estilemas do art-déco.

\section{Mobiliário Moderno}

Deve-se salientar que a introdução do mobiliário moderno em Campinas se deu por meio de Penteado já em 1934, somente dois anos após a chegada de mobiliário de aço moderno na capital em 1932, como relatado pela imprensa carioca:

Realizou-se, ontem, às 5 horas da tarde, no edifício Olinda, a exposição do apartamento moderno, que o arquiteto russo Gregori Warchavchik racionalizou em todos os elementos de construção, de móveis e de outras utilidades para servirem à vida do homem moderno (Correio da Manhã. Rio de Janeiro, 06.01.1932) 
Pela primeira vez nesta capital são utilizados móveis de aço! (O jornal Rio de Janeiro, 06.01. 1932). (SANTOS,1995, p.44)

Conclui-se que Penteado ou importou o mobiliário exposto na sua residência modernista ou encomendou a Warchavchik, posto que: a produção de um mobiliário moderno no Brasil, na década de 1930 estava restrita ao grupo formado por artistas como Lasar Segall, John Graz, Cássio M'Boi, o arquiteto Warchavchik e Theodor Heubeger, esse último ligado à animação cultural. Produziam artesanalmente esses móveis em seus próprios ateliers, curiosamente móveis que deveriam ser produzidos industrialmente e em larga escala.

A primeira loja a comercializar móveis modernos no Brasil foi Galeria Casa \& Jardim, fundada no Rio de Janeiro, em 1926, de propriedade de Heuberger. Lá era vendida uma linha moderna de móveis rústicos executados em nó de pinho. Só em 1938 uma filial seria aberta em São Paulo com o nome "A Forma Decorativa S.A".

Assim como Penteado havia encomendado as luminárias da casa ao arquiteto Warchavchik, poderia também ter encomendado as cadeiras de aço tubulares expostas na laje-terraço, como pode ser atestada pelas fotos de seu álbum.

Entre 1928 e 1933 Warchavchik desenvolveu uma completa linha de móveis abrangendo uma diversificada gama de tipos e modelos, todos eles executados segundo os princípios básicos da modernidade. Os principais materiais utilizados eram a madeira, principalmente a imbuía lustrada ou esmaltada em cores, os tubos de metal cromado, o couro, tecidos e veludos para estofamentos. (SANTOS, 1995, p.44)

Para finalizar, pode-se dizer que a casa modernista de Mário Penteado (5) sintetiza todo o momento histórico de modernização do espaço urbano pelo qual a cidade passava, e nesse contexto sua arquitetura representou um marco arquitetônico.

A partir da singular casa modernista, Penteado desenvolveu uma seqüência de projetos residenciais neocoloniais e outros poucos art déco, o que certamente atendia melhor ao gosto dos clientes. O conjunto de sua obra reflete o período de grandes discussões 
conceituais sobre arquitetura que vivenciou, e apresenta um repertório de edificações que indica a coexistência de vertentes arquitetônicas; de um lado, a acadêmica, expressada pelos estilos em voga, a saber, o neocolonial e o art déco, e por outro lado, a vertente moderna, embasada sobretudo pelos princípios modernos apregoados por Le Corbusier.

Cumpre salientar a importância da reflexão sobre a inclusão dessas obras coetâneas às realizações da arquitetura moderna brasileira das décadas de 1930 e 1940, na seleção de nosso patrimônio arquitetônico. 


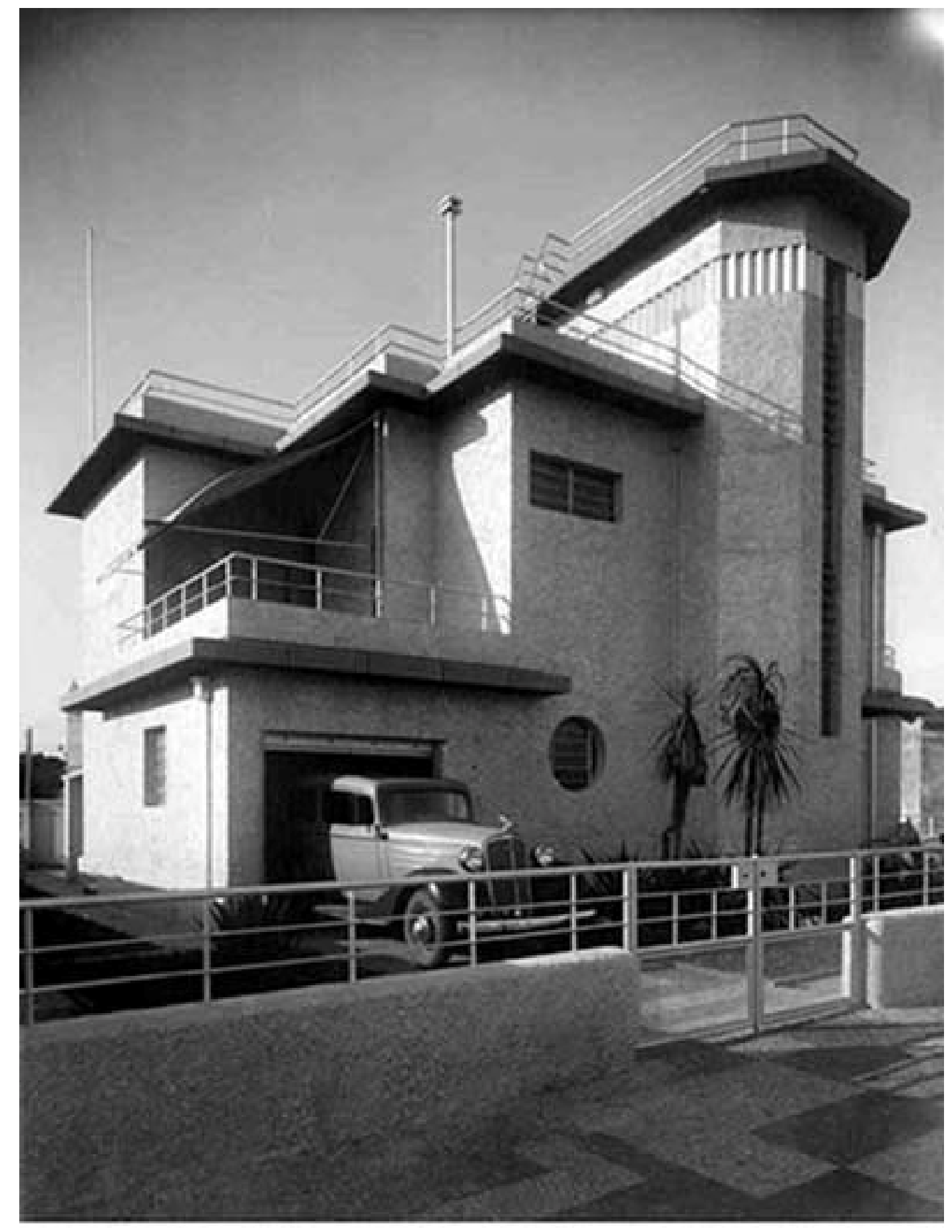

FIGURA 1 - Residência José Ferreira Penteado /1934. Casa Modernista. Fonte: Centro de Audio-Visual/ FAU-PUCC. 


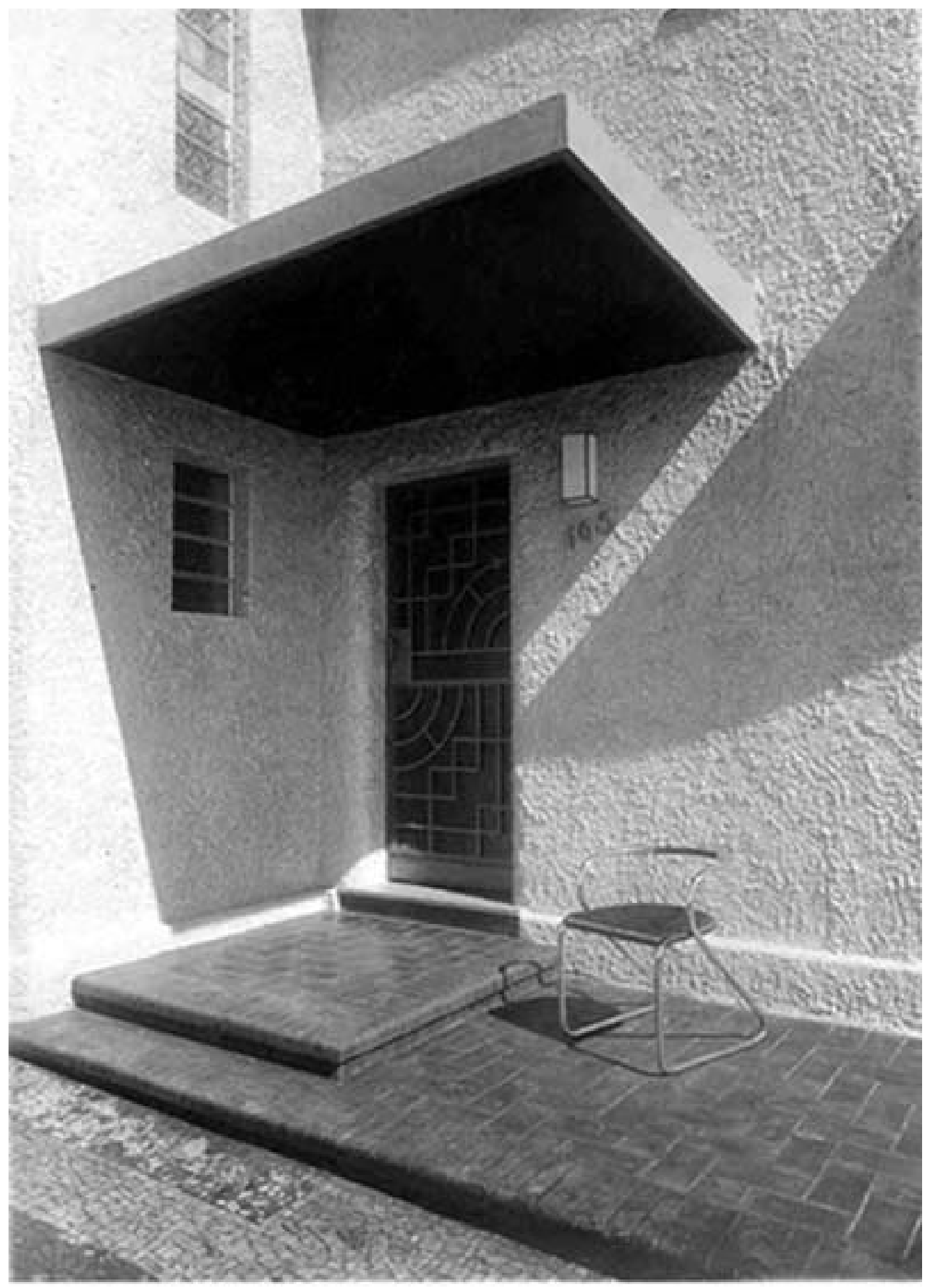

FIGURA 2 - Luminária de Warchavchik ao lado da porta de entrada. Fonte: Centro de Áudio-Visual/ FAU-PUCC. 


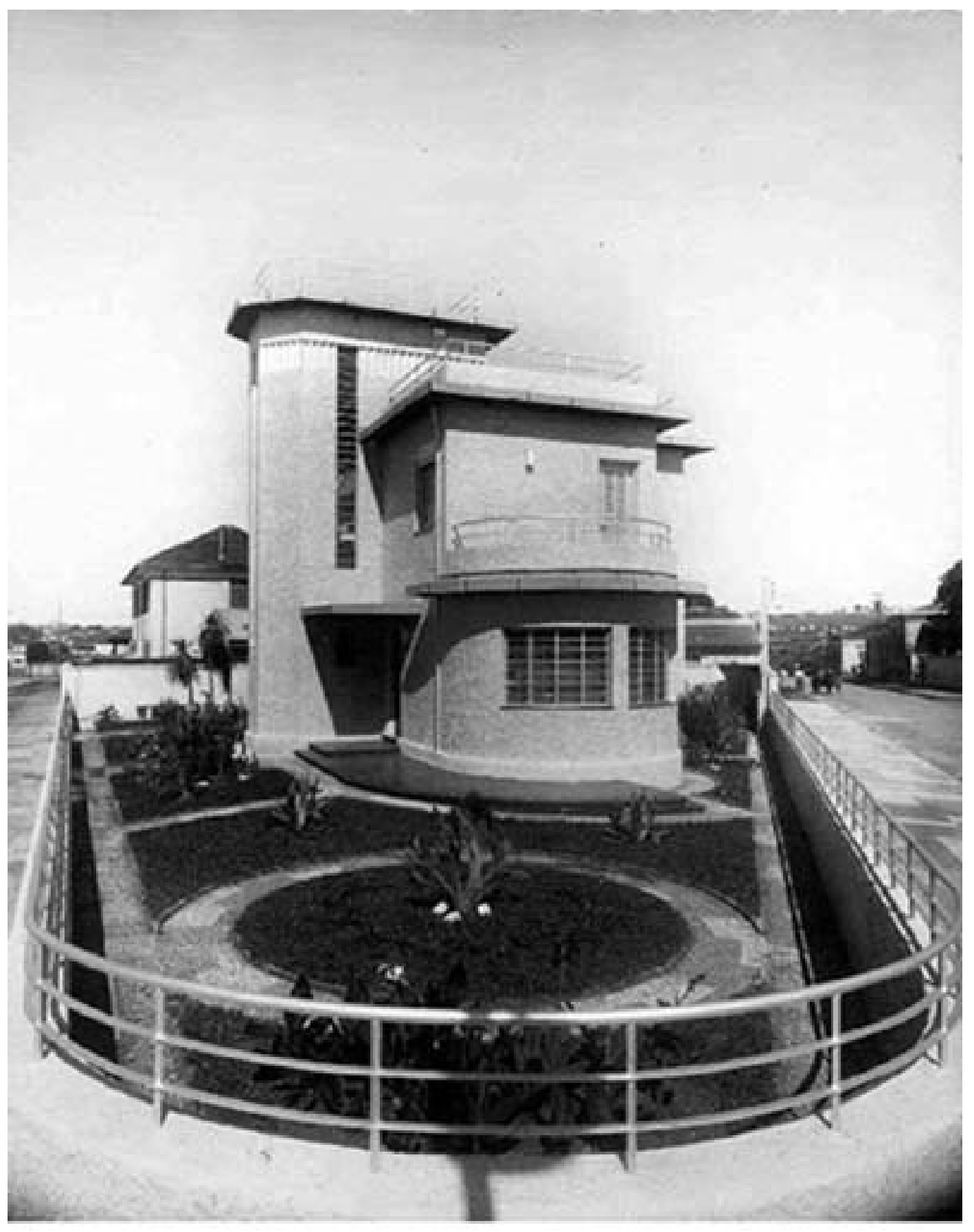

FIGURA 3 - Carroça ao fundo contrasta com a modernidade plástica da edificação. Fonte: Centro de Áudio-Visual/ FAU-PUCC. 


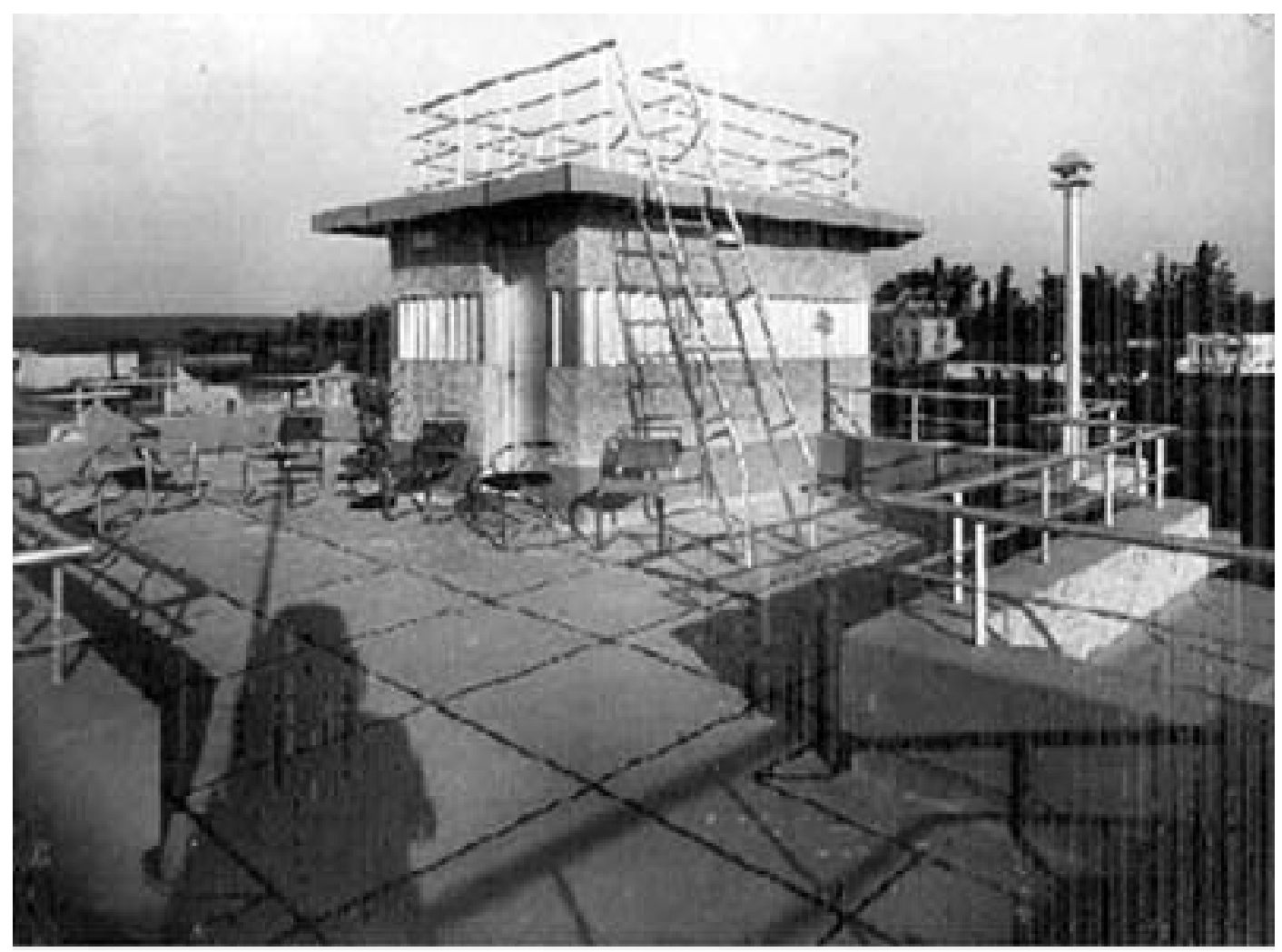

FIGURA 4 - Mobiliário moderno exposto na laje-terraço, cadeira da Bauhaus (projeto Mart Stan - 1928), abaixo da escada. Fonte: Centro de Áudio-Visual/ FAUPUCC.

\section{Notas}

(1) Em nota publicada no Boletim Semanal do Rotary Club de 17/9/1939 consta a seguinte informação: "[...] Mário Penteado, no próximo sábado, deverá deixar Campinas com destino aos Estados Unidos da América do Norte, onde deverá representar o Brasil, como delegado oficial no Congresso Internacional de Arquitetura, a realizar-se de 23 a 30 de setembro, em Washington. Mário Penteado, por indicação honrosa do Instituto dos Arquitetos do Rio de Janeiro, foi nomeado pelo Presidente da República para representar o nosso país no referido Congresso".

(2) Lista de obras de Mário Penteado publicadas na revista AU: abr./maio de 1937 - residência José Ferreira Penteado; set./out. de 1937 - Instituto Hospitalar Penido Burnier; jul./ago. de 1938 - residência; maio/jun. de 1939 Casa de Saúde Bierrenbach de Castro; jul./ago. de 1939 - residência João Lech Jr.; nov./dez. de 1939 - residência Leôncio Queiroz; jul./ago. de 1940 - residências Múcio Murgel e Mário Penteado; set./dez. de 1940 - residência José Estevan Teixeira Mendes.

(3) Revista Arquitetura e Urbanismo - Órgão Oficial do Instituto de Arquitetos do Brasil, revista bimestral que teve seu primeiro número editado em maio/jun. de 1936. Era uma das poucas publicações voltadas ao exercício da profissão do arquiteto no Brasil, editada no Rio de Janeiro. Além da AU, os arquitetos contavam também com a 
Revista Municipal de Engenharia da Prefeitura do Distrito Federal (1º número junho de 1932) e a Acrópole (1938). A $\mathrm{AU}$ era um importante veículo de propagação dos debates sobre a arquitetura (através da revista os arquitetos mantinham-se atualizados: apresentava as conferências de Le Corbusier em 1937, Congressos Panamericanos).

(4) Presidiram o IAB respectivamente nas gestões de 1933-1934 (Roberto Magno de Carvalho), 1934-1936 (Augusto Vasconcellos Jr), 1943-1946 (Paulo de Camargo Almeida) e 1946-1949 (Firmino Fernandes Saldanha)

(5) Encontra-se em processo de tombamento, desde 2001, pelo Conselho de Patrimônio Artístico e Cultural de Campinas, Condepacc. Processo № 013/2001.

\section{Referências bibliográficas}

LEMOS, Carlos A C. Arquitetura contemporânea. In: História Geral da Arte no Brasil. São Paulo: Instituto Moreira Salles, 1983.

SANTOS, Maria Cecília Loschiavo dos. Móvel Moderno no Brasil. São Paulo: Studio Nobel/ FAPESP/ Universidade de São Paulo, 1995.

SOUZA, Abelardo de. Arquitetura no Brasil: depoimentos. São Paulo: Diadorim/ Universidade de São Paulo, 1978.

ZAKIA, Silvia A P. Mário Penteado: arquiteto e obra. Campinas, 2004. Dissertação (Mestrado) - Centro de Ciências Exatas Ambientais e de Tecnologias da Pontifícia Universidade Católica de Campinas, Campinas, 2004.

* Arquiteta. Mestre em História do Urbanismo pelo Centro de Ciências Exatas Ambientais e Tecnologias da Pontifícia Universidade Católica de Campinas.

A obra do arquiteto Mário Penteado foi objeto de pesquisa da dissertação intitulada "Mário Penteado: arquiteto e obra”, defendida pela autora na PUCC, realizada com apoio da Capes, tendo como orientador o professor doutor Ricardo Marques de Azevedo. 